\title{
Numerical Study of Burning of Biomass in Fixed Bed
}

\author{
Chamga Tchana Armand ${ }^{1,2 *}$, Obounou Akong2,3, Beguide Bonoma ${ }^{4}$ \\ ${ }^{1}$ Unit for Research and Doctoral Studies in Physics and Applications, Postgraduate School of Science, Technology and Geoscience, \\ University of Yaounde 1, Yaounde, Cameroon \\ ${ }^{2}$ Department of Physics, Faculty of Sciences, University of Yaounde 1, Yaounde, Cameroon \\ ${ }^{3}$ Laboratory of Analysis of Energy Technologies and the Environment (LATEE), University of Yaounde 1, Yaounde, Cameroon \\ ${ }^{4}$ Department of Physics, ENS Yaounde, University of Yaounde 1, Yaounde, Cameroon \\ Email: *chamgatchana@yahoo.fr, *armand.chamga-tchana@coria.fr
}

How to cite this paper: Armand, C.T., Akong, O. and Bonoma, B. (2019) Numerical Study of Burning of Biomass in Fixed Bed. Energy and Power Engineering, 11, 35-57.

https://doi.org/10.4236/epe.2019.112003

Received: January 18, 2019

Accepted: February 18, 2019

Published: February 21, 2019

Copyright $\odot 2019$ by author(s) and Scientific Research Publishing Inc. This work is licensed under the Creative Commons Attribution International License (CC BY 4.0).

http://creativecommons.org/licenses/by/4.0/

\begin{abstract}
The combustion of biomass not only falls in energy production, but also in the recovery of waste. The treatment method most used for the recovery of waste is incineration because this method of treatment can minimize the volume of waste. In this work, it comes to realize a numerical modeling of the combustion of biomass in a fixed grate furnace. A literature review allowed us to describe the stages of combustion in terms of mathematical equations. Taking into account the results of elemental analysis and immediate analysis, solid and gaseous species used to simulate their transport equations are: Dry fuel (biomass), char, $\mathrm{CH}_{4}, \mathrm{O}_{2}, \mathrm{CO}, \mathrm{H}_{2} \mathrm{O}, \mathrm{CO}_{2}$, and $\mathrm{N}_{2}$. From equations of energy transportation, we deducted the TS temperature of the solid fuel bed and $\mathrm{Tg}$ of gas. Subsequently, we simulated the resolution 1-D transport equations using a computer code written by us and this on the basis of mathematical modeling of the transport equations. This 1-D unstationnary model takes into account the different stages of load transformation. In this calculation code, we used the explicit Euler method for space discretization, and for the time resolution, we used an implicit method which solves stiff problems of differential equations to ordinary derivatives. The results are satisfactory because the calculated numerical profiles follow the experimental profiles, such as, the temperature profiles, the loss of mass of the fuel bed and the speed of propagation of the flame front.
\end{abstract}

\section{Keywords}

Multiphasic Combustion, Biomass, Modeling, Numerical Computation, Fixed Bed 


\section{Introduction}

Nowadays, the energies have an important place in the life of man and our current level of development requires an energy consumption increasingly growing. To meet this great need for energy, man has long had use of fossil fuels, rejecting into the atmosphere huge amounts of pollutants, including $\mathrm{CO}_{2}$. Given the need to protect the environment by reducing the emission of greenhouse gases (GHGs), uncertainty about the uncertain future of fossil fuels, and especially our strong energy demand research have turned to new energy sources, which one of the main is combustion of biomass.

Renewable energies are numerous (biomass, solar, geothermal, waste, wind, hydraulic) and energy research grants them special attention. Here we focus especially on the use of biomass as solid fuel that can be burned in a suitable oven to harness the energy released. The technologies used for burning biomass are numerous and the choice of a burner may depend on such factors as the nature of the fuel and its moisture content.

The combustion of biomass not only falls in energy production, but also in the recovery of waste. The treatment method most used for the recovery of waste is incineration because this method of treatment can minimize the volume of waste.

The multiphase combustion is a phenomenon that is part of our daily life: Cooking food using firewood or sawdust furnaces, incineration of household waste (HW), to name a few. This phenomenon, which seems simple, actually falls a physicochemical complexity. The multiphase combustion involves the phases solid, liquid and gaseous, noted, however, that obtaining a good combustion quality depends on the quality of fuel distribution on the grid, on the turning efficiency ensuring the best touch fuel/oxidizer to a sufficient temperature in drying zone-pyrolyse and on the nature of the fuel used. Several studies have already been conducted in this area: This is the case of Shin and Choi [1] who are studying the burning of wood particles on fixed bed. Reaction rates are available in several chemical kinetic models [2]-[7]. Yann [8] presents the characteristics of fixed grate incinerators and Benkoussas et al. [9] are interested to thermal degradation of the wood particles.

This work is in search of a numerical method to solve equations, and for approaching the experimental results. So we proposed writing a numerical computation code that allows to numerically modeling the combustion of solid biomass particles. This numerical modeling is a combustion control to optimize the conversion of fuel into heat and reduce the production of pollutants. Controlling combustion involves controlling its various stages, namely drying, pyrolysis and combustion of the gases and the carbon residue released during the pyrolysis phase. One of the peculiarities of our numerical model is to use a stiff method for the resolution of the temporal part, which makes the numerical model more stable and more robust.

\section{Combustion in Solid Fuel Bed}

The combustion of a load is characterized by a complex set of exothermic chem- 
ical reactions due to rapid oxidation of the fuel elements. The kinetics of the combustion of a load involves several stages from the drying to the heterogeneous and homogeneous combustion.

On a smoldering wood particle (Figure 1), the main areas where the three preceding steps take place, can be observed (drying, pyrolysis, combustion of solid and gaseous phases). We can observe in this figure that the central section is made of raw wood and surrounded by a zone where the drying takes place. The following outer layer constitutes the pyrolysis zone and therefore devolatilization, and finally the last layer is the combustion zone of the carbonaceous residue (coke plant).

Combustion is a complex process that involves several related equations together and acting on two levels: In solid phase and gas phase.

There is a significant interaction between the combustion in the solid phase and in the gas phase. This interaction is shown in Figure 2.

The main phenomena that take place in the solid phase are: drying or evaporation, pyrolysis and coal combustion. The heat transfer between solid particles here is by conduction and radiation. In this phase, the moisture produced during the drying as well as the volatiles produced during the pyrolysis and the carbon monoxide produced during the combustion of the coal will be returned to the gas phase. In the gas phase, there is therefore combustion of gaseous products from the solid phase. As another interaction, it is the gaseous phase that provides the solid phase with the oxygen necessary for coal combustion, and the heat transfer between these two phases is by convection.

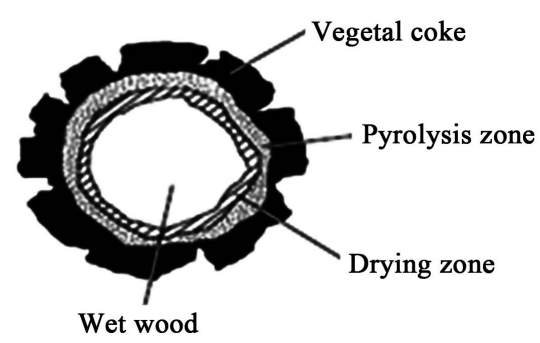

Figure 1. Representative section of burning wood particle.
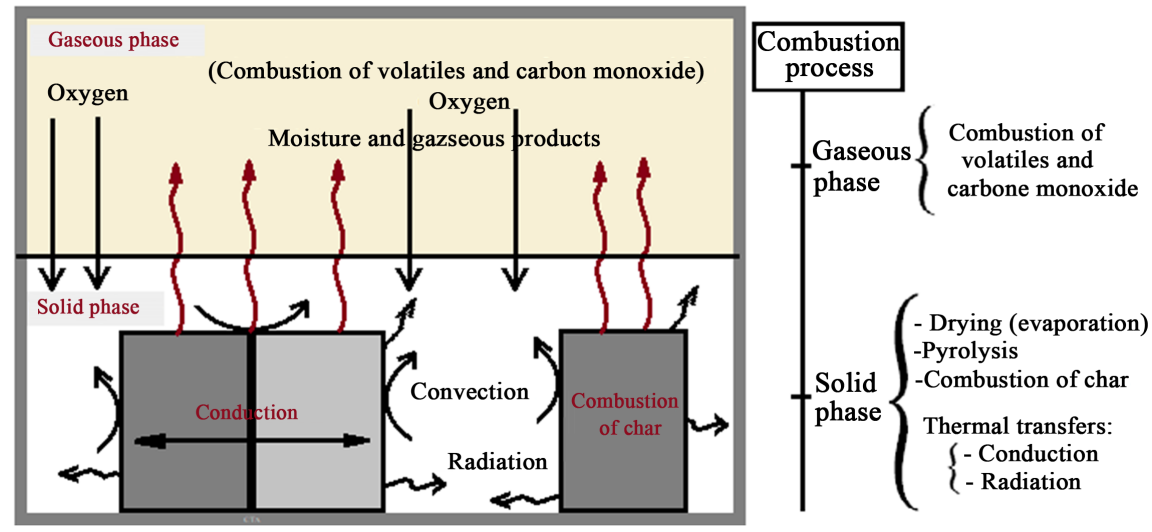

Figure 2. Combustion: Interaction between solid phase and gas phase. 
The combustion process thus leads to the destruction of the solid fuel. During its degradation in an incinerator, or a burner, the solid fuel degrades in the presence of oxygen. This combustion results in a gradual decrease of the height of the solid fuel bed into the incinerator, as shown in Figure 3. The carbonaceous residue obtained after the pyrolysis phase can also be gasified by steam or by the $\mathrm{CO}_{2}$ for subsequent use. After combustion, there is production of ashes which are gradually cooled by the air injected into the bed always at room temperature.

Figure 3 which shows a schematic view of the process of combustion of the wood particles in the fuel bed, one obtains the gradual decrease in height of the fuel bed.

To implement all these steps, here we have conducted a 1-D modeling of the combustion of the wood particles having a constant diameter and assumed the same for all particles.

\section{Experimental Device}

Figure 4 shows the experimental device. The combustion chamber of the device is a cylinder of $18 \mathrm{~cm}$ internal diameter. It is thermally insulated by a refractory wall $3.5 \mathrm{~cm}$ thick, surrounded by an outer steel jacket of $0.3 \mathrm{~cm}$ thick. The grate to the base is perforated with holes to allow air entry.

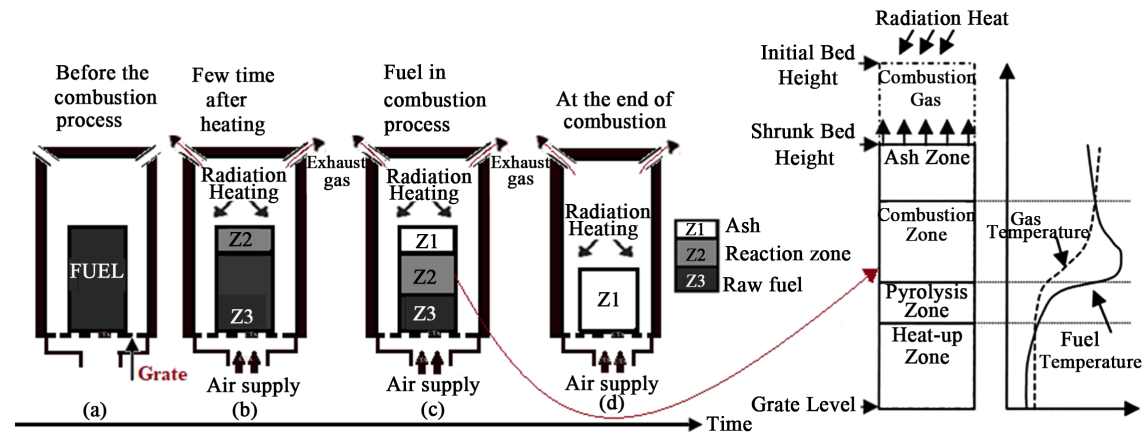

Figure 3. Schematic of combustion in the solid fuel bed.

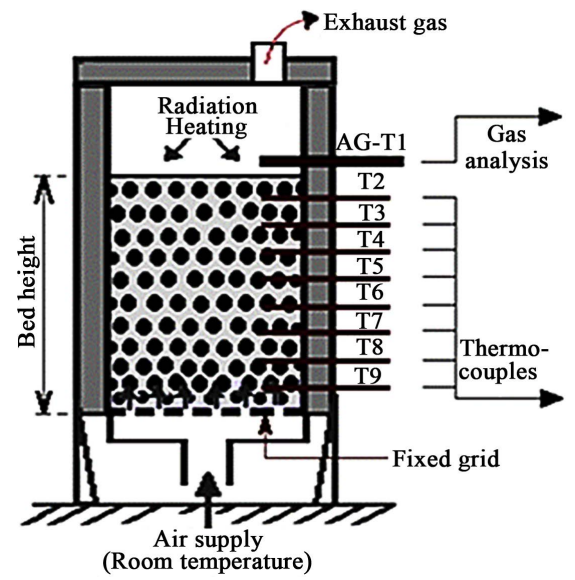

Figure 4. Experimental furnace. 
The fuel is made of wooden particles having a density $\rho=600 \mathrm{~kg} / \mathrm{m}^{3}$, of radius of between 1 and $3 \mathrm{~cm}$ and its PCS is $19.8975 \mathrm{MJ} / \mathrm{kg}$. The height of the fuel bed is $45 \mathrm{~cm}$. The air enters under the grate at a speed of $0.05 \mathrm{~m} / \mathrm{s}$.

Table 1 presents the results of elemental and immediate analyzes of wood particles used as fuel.

\section{Mathematical Description of the Combustion Process}

\subsection{Conservation Equations}

The conservation equations are written for solid and gaseous phases. These conservation equations applied to a volume element can describe the instantaneous evolution of different variables anywhere in the field. One thus obtains transport equations whose general form is:

$$
\underbrace{\frac{\partial \rho \varnothing}{\partial t}}_{\text {unstationnary term }}+\underbrace{\nabla \cdot \rho u \varnothing}_{\text {convection term }}=\underbrace{\nabla \cdot\left(J_{\varnothing}\right)}_{\text {diffusion term }}+\underbrace{S_{\varnothing}}_{\text {source term }}
$$

where $\varnothing$ represents the variables of mass, the total enthalpy (energy) or species; $J_{\varnothing}$ represents the broadcast stream, $S_{\varnothing}$ source terms, $\rho$ the densities of the solid or gaseous species and $u$ the speeds of evolution of species.

View test results in Table 1, the transport equations to solve are:

$$
\begin{aligned}
& \mathrm{H}_{2} \mathrm{O}: \frac{\partial\left(\varepsilon_{b} \rho_{g} Y_{\mathrm{H}_{2} \mathrm{O}}\right)}{\partial t}+\frac{\partial\left(\rho_{g} v_{g} Y_{\mathrm{H}_{2} \mathrm{O}} \varepsilon_{b}\right)}{\partial x}=\frac{\partial}{\partial x}\left(\varepsilon_{b} D_{a, \text { eff }} \rho_{g} \frac{\partial Y_{\mathrm{H}_{2} \mathrm{O}}}{\partial x}\right)+R_{\mathrm{H}_{2} \mathrm{O}} \\
& \mathrm{O}_{2}: \frac{\partial\left(\varepsilon_{b} \rho_{g} Y_{\mathrm{O}_{2}}\right)}{\partial t}+\frac{\partial\left(\rho_{g} v_{g} Y_{\mathrm{O}_{2}} \varepsilon_{b}\right)}{\partial x}=\frac{\partial}{\partial x}\left(\varepsilon_{b} D_{a, \text { eff }} \rho_{g} \frac{\partial Y_{\mathrm{O}_{2}}}{\partial x}\right)+R_{\mathrm{Y}_{\mathrm{O}_{2}}} \\
& \mathrm{CH}_{4}: \frac{\partial\left(\varepsilon_{b} \rho_{g} Y_{\mathrm{CH}_{4}}\right)}{\partial t}+\frac{\partial\left(\rho_{g} v_{g} Y_{\mathrm{CH}_{4}} \varepsilon_{b}\right)}{\partial x}=\frac{\partial}{\partial x}\left(\varepsilon_{b} D_{a, e \text { eff }} \rho_{g} \frac{\partial Y_{\mathrm{CH}_{4}}}{\partial x}\right)+R_{Y_{\mathrm{CH}_{4}}} \\
& \mathrm{CO}_{2}: \frac{\partial\left(\varepsilon_{b} \rho_{g} Y_{\mathrm{CO}_{2}}\right)}{\partial t}+\frac{\partial\left(\rho_{g} v_{g} Y_{\mathrm{CO}_{2}} \varepsilon_{b}\right)}{\partial x}=\frac{\partial}{\partial x}\left(\varepsilon_{b} D_{a, e f f} \rho_{g} \frac{\partial Y_{\mathrm{CO}_{2}}}{\partial x}\right)+R_{\mathrm{C}_{\mathrm{CO}_{2}}} \\
& \mathrm{CO}: \frac{\partial\left(\varepsilon_{b} \rho_{g} Y_{\mathrm{CO}}\right)}{\partial t}+\frac{\partial\left(\rho_{g} v_{g} Y_{\mathrm{CO}} \varepsilon_{b}\right)}{\partial x}=\frac{\partial}{\partial x}\left(\varepsilon_{b} D_{a, e f f} \rho_{g} \frac{\partial Y_{\mathrm{CO}}}{\partial x}\right)+R_{Y_{\mathrm{CO}}}
\end{aligned}
$$

Table 1. Elementary and immediate analysis of fuel.

\begin{tabular}{cccc}
\hline \multicolumn{2}{c}{ Immediate analysis (wt\%) } & \multicolumn{2}{c}{ Elemental analysis (wt\%) } \\
\hline Humidity & $8.2 \%$ gross & $\mathrm{C}$ & $46.9 \%$ dry \\
& & & $49.1 \%$ gross \\
Volatile rate & $77.1 \%$ dry & $\mathrm{H}$ & $6.4 \%$ dry \\
& $69.7 \%$ gross & & $6.68 \%$ gross \\
Ash content & $1.2 \%$ dry & O (by difference) & $38.3 \%$ dry \\
& $1.3 \%$ gross & & $43.86 \%$ gross \\
Fixed carbon content & $13.5 \%$ dry & $\mathrm{N}$ & $0.59 \%$ dry \\
& $29 \%$ gross & & $0.36 \%$ gross \\
\hline
\end{tabular}




$$
\mathrm{N}_{2}: \frac{\partial\left(\varepsilon_{b} \rho_{g} Y_{\mathrm{N}_{2}}\right)}{\partial t}+\frac{\partial\left(\rho_{g} v_{g} Y_{\mathrm{N}_{2}} \varepsilon_{b}\right)}{\partial x}=\frac{\partial}{\partial x}\left(\varepsilon_{b} D_{a, e f f} \rho_{g} \frac{\partial Y_{\mathrm{N}_{2}}}{\partial x}\right)
$$

Energy Transport equation in:

Gas phase:

$$
\frac{\partial\left(\varepsilon_{b} \rho_{g} c_{p g} T_{g}\right)}{\partial t}+\frac{\partial\left(\rho_{g} v_{g} c_{p g} T_{g} \varepsilon_{b}\right)}{\partial x}
$$

Solid phase:

$$
\begin{aligned}
= & \frac{\partial}{\partial x}\left(\lambda_{g} \frac{\partial T_{g}}{\partial x}\right)+h S\left(T_{S}-T_{g}\right)+Q_{g}+Q_{l g} \\
& \frac{\partial\left(\left(1-\varepsilon_{b}\right) \rho_{s} c_{p s} T_{s}\right)}{\partial t}+\frac{\partial\left(\left(1-\varepsilon_{b}\right) \rho_{s} v_{s} c_{p s} T_{s}\right)}{\partial x}
\end{aligned}
$$

Humidity:

$$
\begin{gathered}
=\frac{\partial}{\partial x}\left(\lambda_{\text {eff }} \frac{\partial T_{s}}{\partial x}\right)+h S\left(T_{g}-T_{s}\right)+Q_{s}+Q_{l s} \\
\frac{\partial\left(\left(1-\varepsilon_{b}\right) \rho_{s} Y_{\text {hum }}\right)}{\partial t}+\frac{\partial\left(\left(1-\varepsilon_{b}\right) \rho_{s} v_{s} Y_{\text {hum }}\right)}{\partial x}
\end{gathered}
$$

$$
\begin{aligned}
& =\frac{\partial}{\partial x}\left(\left(1-\varepsilon_{b}\right) D_{s} \rho_{s} \frac{\partial Y_{\text {hum }}}{\partial x}\right)+R_{Y_{\text {hum }}} \\
& \quad \frac{\partial\left(\left(1-\varepsilon_{b}\right) \rho_{s} Y_{\text {Fuel }}\right)}{\partial t}+\frac{\partial\left(\left(1-\varepsilon_{b}\right) \rho_{s} v_{s} Y_{\text {Fuel }}\right)}{\partial x}
\end{aligned}
$$

Dry solid fuel:

$$
=\frac{\partial}{\partial x}\left(\left(1-\varepsilon_{b}\right) D_{s} \rho_{s} \frac{\partial Y_{\text {Fuel }}}{\partial x}\right)+R_{Y_{\text {Fuel }}}
$$

Char:

$$
\frac{\partial\left(\left(1-\varepsilon_{b}\right) \rho_{s} Y_{\text {char }}\right)}{\partial t}+\frac{\partial\left(\left(1-\varepsilon_{b}\right) \rho_{s} v_{s} Y_{\text {char }}\right)}{\partial x}
$$

Ash: $\quad \frac{\partial\left(\left(1-\varepsilon_{b}\right) \rho_{s} Y_{A s h}\right)}{\partial t}+\frac{\partial\left(\left(1-\varepsilon_{b}\right) \rho_{s} v_{s} Y_{A s h}\right)}{\partial x}$

$$
=\frac{\partial}{\partial x}\left(\left(1-\varepsilon_{b}\right) D_{s} \rho_{s} \frac{\partial Y_{\text {char }}}{\partial x}\right)+R_{Y_{\text {char }}}
$$

$$
=\frac{\partial}{\partial x}\left(\left(1-\varepsilon_{b}\right) D_{s} \rho_{s} \frac{\partial Y_{A s h}}{\partial x}\right)+R_{Y_{A s h}}
$$

Continuity equation in the gas phase: $\varepsilon_{b} \frac{\partial\left(\rho_{g}\right)}{\partial t}+\varepsilon_{b} \frac{\partial\left(\rho_{g} v_{g}\right)}{\partial x}=R_{g}$

Continuity equation in the solid phase: $\frac{\partial\left(\left(1-\varepsilon_{b}\right) \rho_{s}\right)}{\partial t}+\frac{\partial\left(\left(1-\varepsilon_{b}\right) \rho_{s} v_{s}\right)}{\partial x}=R_{s}$

\subsection{Modeling the Combustion of Solid Particles}

During combustion of the wood particles, the phenomena of drying, pyrolysis, homogeneous and heterogeneous combustion act to reduce fuel in combustion products. The following equations will model these different physico-chemical phenomena.

\subsubsection{Modeling of Drying}

Drying is the evaporation process of the water contained in the fuel. It corres- 
ponds to the reaction:

$$
\text { Wet biomass } \rightarrow \text { Dry biomass }+ \text { Moisture }
$$

Drying the reaction rate is given by the Arrhenius equation [9] [10]:

$$
R_{\text {vap }}=A_{v a p} \mathrm{e}^{\frac{-E a_{v a p}}{R T_{s}}} Y_{h} \rho_{a p}
$$

where $A_{v a p}, E a_{v a p}, T_{S}, Y_{h}$ and $\rho_{a p}$ are respectively the pre-exponential factor $\left(A_{\text {vap }}=5.13 \times 10^{10}[11]\right)$, the activation energy ( $E a_{\text {vap }}=88000$ [11]), the temperature of the solid, the mass fraction of water in the fuel and the density of wet biomass.

\subsubsection{Modeling of Pyrolysis}

Pyrolysis is the degradation of the organic portion of the dry fuel under the effect of heat and leading to the formation of carbonaceous residue (coal) and the release of volatile gases. We have considered here for the process of thermal degradation of the wood particles in a two-step mechanism (blasi [12]):

$\checkmark$ The first step corresponds to the production of volatile by the following reaction:

$$
\text { Solid fuel } \rightarrow \text { Volatile }
$$

The speed of this devolatilization reaction is given by (blasi [12]):

$$
R_{d e v}=5.6 \times 10^{6} \exp \left(\frac{-10700}{T_{S}}\right) M_{S_{-} \text {Fuel }}
$$

where $M_{S_{-} \text {Fuel }}$ is the mass of dry fuel present in each moment in the combustion chamber and $T_{S}$ the temperature of the solid fuel.

Here the volatile is supposed to be $\mathrm{CH}_{4}[1]$.

$\checkmark$ The second step is the production of coal according to the reaction:

$$
\text { Solid fuel } \rightarrow \text { Char }
$$

The char production rate is given by [13]:

$$
R_{\text {char }}=2.66 \times 10^{10} \exp \left(\frac{-12800}{T_{S}}\right) M_{S_{-} \text {Fuel }}
$$

\subsubsection{Modeling of Homogeneous Combustion}

Taking account of the elemental analysis of this solid fuel, the gaseous species that undergo homogeneous combustion $\left(\mathrm{CH}_{4}, \mathrm{CO}\right)$ burn according to the reactions:

$$
\mathrm{CH}_{4}+\frac{3}{2} \mathrm{O}_{2} \rightarrow \mathrm{CO}+2 \mathrm{H}_{2} \mathrm{O} \quad \text { [14] }
$$

With the reaction rate [13] [14] [15]:

$$
\begin{gathered}
R_{g 1}=A 2\left[\mathrm{CH}_{4}\right]^{a}\left[\mathrm{O}_{2}\right]^{b} \exp \left(-\frac{E_{a 2}}{T_{g}}\right) \\
\mathrm{CO}+\frac{1}{2} \mathrm{O}_{2} \rightarrow \mathrm{CO}_{2} \quad[16]
\end{gathered}
$$


With the rate of reaction [17] [18]:

$$
R_{g 2}=A 3[\mathrm{CO}]\left[\mathrm{H}_{2} \mathrm{O}\right]^{a}\left[\mathrm{O}_{2}\right]^{b} \exp \left(-\frac{E_{a 3}}{T_{g}}\right)
$$

$\alpha=0.5$ is a weighting factor, the average temperature $T_{e}$ to which the reaction rate is calculated is given by [13] [19]:

$$
T_{e}=\alpha T_{g}+(1-\alpha) T_{s} \text { si } T_{g} \leq T_{s} ; T_{e}=T_{g} \text { si } T_{g}>T_{s}
$$

The constants $A i, \quad E_{a i} / R \quad(i=2,3,4), a$ and $b$ are given in Table 2 .

\subsubsection{Modeling of Heterogeneous Combustion}

Char combustion may be described by the following two processes:

$$
\mathrm{C}+\mathrm{O}_{2} \rightarrow \mathrm{CO}_{2} \text { and } 2 \mathrm{C}+\mathrm{O}_{2} \rightarrow 2 \mathrm{CO}
$$

By combining these two equations, we obtain: [13]

$$
\mathrm{C}+\varphi \mathrm{O}_{2} \rightarrow 2(1-\varphi) \mathrm{CO}+(2 \varphi-1) \mathrm{CO}_{2}
$$

The constant $\varphi$ is given by:

$$
\varphi=\frac{2+f}{2(1+f)}
$$

where $f$ is the $\mathrm{CO} / \mathrm{CO}_{2}$ ratio $\left(f=\frac{\mathrm{CO}}{\mathrm{CO}_{2}}\right)$. It is given by [2]:

$$
f=12 \mathrm{e}^{\frac{-3300}{T_{s}}}
$$

The speed of the carbon combustion reaction is written as [20]:

$$
R_{C_{(s)}}=\frac{\pi d_{p}^{2} M_{C} k_{C_{(s)}} P_{\mathrm{O}_{2}}}{\varphi}
$$

where $d_{p}$ is the diameter of the particle, $M_{c}$ the molar mass of carbon, $P_{\mathrm{O}_{2}}$ the partial pressure of oxygen and $k_{C_{(s)}}$ the rate constant which is given by [20]:

$$
k_{C_{(s)}}=\frac{1}{\frac{1}{k_{c} \Omega_{a c t}}+\frac{1}{k_{d}}}
$$

This rate constant has three terms, namely:

$\rightarrow$ The ash factor which takes into account the effect of the presence of ash on the oxidation kinetics and whose expression can be written [20]:

$$
\Omega_{a c t}=\frac{Y_{C_{(s)}}}{Y_{C_{(s)}}+Y_{a s h}}
$$

Table 2. Reaction parameters for the combustion of volatile.

\begin{tabular}{cccccc}
\hline Reaction & $\boldsymbol{A i}$ & $\boldsymbol{E}_{\mathrm{a} \text { I }} / \boldsymbol{R}[\mathrm{K}]$ & $\boldsymbol{a}$ & $\boldsymbol{b}$ & Refs. \\
\hline $\mathrm{Rg} 1$ & 24,157 & 0.7 & 0.8 & {$[14]$} \\
$\mathrm{Rg} 2$ & $1.6 \times 10^{10}$ & 15,105 & 0.5 & 0.5 & {$[17][18]$} \\
\hline
\end{tabular}


where $Y_{C_{(s)}}$ and $Y_{a s h}$ are respectively the mass fractions of carbon residue (char) and ash.

$\rightarrow$ The rate constant due to chemical kinetics which is given by [10]:

$$
k_{c}=1.175 T_{s} \mathrm{e}^{\frac{-9000}{T_{s}}}
$$

where $T_{S}$ is the temperature of the solid.

$\rightarrow$ The mass transfer coefficient $k_{d}$ which is defined by [20]:

$$
k_{d}=\frac{S h D_{O_{2, m}}}{d_{p}}
$$

where $D_{O_{2, m}}$ is the mass diffusion coefficient of oxygen in air and $S h$ the Sherwood number defined by [21]:

$$
S h=2+0.6 R e^{0.5} S c^{1 / 3}
$$

where $S c$ is the Schmidt number given by: $S c=\frac{\mu_{g}}{\rho_{g} D_{O_{2, m}}}$, and $R e$ the Reynolds number whose expression is: $R e=\rho_{g} u_{g} d_{p} / \mu_{g}$ [22], where $u_{g}$ represents the superficial gas velocity, $\mu_{g}$ the dynamic viscosity of the gas defined at the temperature $T_{g}$ of the gas by the expression [13]:

$$
\mu_{g}=1.98 \times 10^{-5}\left(\frac{T_{g}}{300}\right)^{2 / 3}
$$

And $\rho_{g}$ the density of the gas calculated at the temperature of the gas phase at a specific point of the bed; it is calculated according to the equation:

$$
\rho_{g}=\frac{P}{R T_{g}\left(\frac{Y_{\mathrm{O}_{2}}}{M_{\mathrm{O}_{2}}}+\frac{Y_{\mathrm{N}_{2}}}{M_{\mathrm{N}_{2}}}\right)}
$$

$M_{\mathrm{O}_{2}}$ and $M_{\mathrm{N}_{2}}$ are respectively the molar masses of dioxygen and dinitrogen, and $P$, the gas pressure. Taking air as the inlet gas, we have: $Y_{\mathrm{O}_{2}}=23.3 \%$, $Y_{\mathrm{N}_{2}}=76.7 \%$.

The Sherwood number can also be written [23]:

$$
S h=J S c^{1 / 3} R e
$$

where $J$ which allows taking into account the diffusion of the gaseous mixture flowing through the fuel bed is the Colburn factor whose expression is [22] [23]:

$$
J=\frac{1}{\varepsilon_{b}}\left(\frac{0.765}{R e^{0.82}}+\frac{0.365}{R e^{0.368}}\right)
$$

With $\varepsilon_{b}$, the porosity of the fuel bed and the expression of which is:

$$
\varepsilon_{b}=1-\frac{\rho_{a p p, 0}}{\rho_{s, 0}}
$$

where $\rho_{a p p, 0}$ is the apparent density determined experimentally ( $\rho_{\text {app }, 0}=550 \mathrm{~kg} / \mathrm{m}^{3}$ for wood particles), and $\rho_{s, 0}$ the initial density of solid biomass particles estimated from the formula:

$$
\rho_{s, 0}=\frac{1}{\frac{H_{b}}{\rho_{\text {water }}}+\frac{1-H_{b}}{\rho_{S_{-} \text {Fuel }}^{\text {dry }}}}
$$


With $H_{b}$, the moisture on crude supplied by immediate analysis, $\rho_{\text {water }}$ the density of water, and $\rho_{S_{-} \text {Fuel }}^{\text {dry }}$, the density of dry solid biomass particles.

The density of the solid during the thermal conversion is calculated from the following relationship:

$$
\rho_{s}=\frac{1}{\frac{Y h}{\rho_{\text {water }}}+\frac{Y_{v}}{\rho_{M V}}+\frac{Y_{C_{(s)}}}{\rho_{C(s)}}+\frac{Y_{A s h}}{\rho_{A s h}}}
$$

where $Y h, Y_{v}, Y_{C_{(s)}}, Y_{A s h}$ are respectively the mass fractions of moisture, volatile, char and ash, and $\rho_{\text {water }}, \rho_{M V}, \rho_{C(s)}, \rho_{A s h}$, respectively the densities of water, volatiles, char and ash.

\subsection{Transport Equations to Solve}

\subsubsection{Equations of the Gas Phase}

The continuity equation for the gas phase is given by [15]:

$$
\varepsilon_{b} \frac{\partial\left(\rho_{g}\right)}{\partial t}+\varepsilon_{b} \frac{\partial\left(\rho_{g} v_{g}\right)}{\partial x}=R_{g}
$$

The transport equation of the gaseous species is given by [13]:

$$
\frac{\partial\left(\varepsilon_{b} \rho_{g} Y_{i g}\right)}{\partial t}+\frac{\partial\left(\rho_{g} v_{g} Y_{i g} \varepsilon_{b}\right)}{\partial x}=\frac{\partial}{\partial x}\left(\varepsilon_{b} D_{a, e f f} \rho_{g} \frac{\partial Y_{i g}}{\partial x}\right)+R_{Y_{i g}}
$$

With ig $=\mathrm{H}_{2} \mathrm{O}, \mathrm{O}_{2}, \mathrm{CH}_{4}, \mathrm{CO}_{2}, \mathrm{CO}$, and $\mathrm{N}_{2}$.

The transport equation of the energy in the gas phase is given by [13] [15] [23]:

$$
\frac{\partial\left(\varepsilon_{b} \rho_{g} c_{p g} T_{g}\right)}{\partial t}+\frac{\partial\left(\rho_{g} v_{g} c_{p g} T_{g} \varepsilon_{b}\right)}{\partial x}=\frac{\partial}{\partial x}\left(\lambda_{g} \frac{\partial T_{g}}{\partial x}\right)+h S\left(T_{S}-T_{g}\right)+Q_{g}+Q_{l g}
$$

where $h$ is the heat transfer coefficient of gas-balance $\left(\mathrm{W} / \mathrm{m}^{2} \mathrm{~K}\right), S$ the specific exchange surface of the bed of particles (here $S=54 \mathrm{~m}^{2} / \mathrm{m}^{3}$ ), $Q_{g}$ the heat gain due to the combustion in gaseous phase $\left(Q_{g}=\sum_{i} r_{i}\left(-\Delta H_{i}\right), r_{i}\right.$ and $\Delta H_{i}$ the speed and the heat of reaction in the gas phase), and $Q_{l g}$ the loss of energy (enthalpy) along the bed wall. $Q_{\lg }$ is given by [15]:

$$
Q_{l g}=\varepsilon_{b}(k / L)\left(T_{g}-T_{0}\right) / \Delta l
$$

where $k$ is the bed conductivity coefficient, $L$ the length/height of the bed, $T_{0}$ the room temperature, and $\Delta l$ the wall thickness.

\subsubsection{Equations of the Solid Phase}

The continuity equation for the solid phase is given by [16]:

$$
\frac{\partial\left(\left(1-\varepsilon_{b}\right) \rho_{s}\right)}{\partial t}+\frac{\partial\left(\left(1-\varepsilon_{b}\right) \rho_{s} v_{s}\right)}{\partial x}=R_{s}
$$

The general form of the transport equation of solid species is given by [16]:

$$
\frac{\partial\left(\left(1-\varepsilon_{b}\right) \rho_{s} Y_{i s}\right)}{\partial t}+\frac{\partial\left(\left(1-\varepsilon_{b}\right) \rho_{s} v_{s} Y_{i s}\right)}{\partial x}=\frac{\partial}{\partial x}\left(\left(1-\varepsilon_{b}\right) D_{s} \rho_{s} \frac{\partial Y_{i s}}{\partial x}\right)+R_{Y_{i s}}
$$


where is = Humidity, dry fuel (solid biomass), char, ash.

The transport equation of the energy in the solid phase is given by [16]:

$$
\begin{aligned}
& \frac{\partial\left(\left(1-\varepsilon_{b}\right) \rho_{s} c_{p s} T_{s}\right)}{\partial t}+\frac{\partial\left(\left(1-\varepsilon_{b}\right) \rho_{s} v_{s} c_{p s} T_{s}\right)}{\partial x} \\
& =\frac{\partial}{\partial x}\left(\lambda_{\text {eff }} \frac{\partial T_{s}}{\partial x}\right)+h S\left(T_{g}-T_{s}\right)+Q_{s}+Q_{l s}
\end{aligned}
$$

$Q_{s}$ is the heat generation due to char combustion $\left(\mathrm{W} / \mathrm{m}^{3}\right)$ given by: $Q_{s}=r_{\text {char }} x \Delta H_{\text {char }}$ where $r_{\text {char }}$ and $\Delta H_{\text {char }}$ represent speed and heat of reaction of char combustion reaction in the solid phase. $Q_{l s}$ is the loss of energy (enthalpy) along the bed wall and is given by [15]:

$$
Q_{l s}=\left(1-\varepsilon_{b}\right)(k / L)\left(T_{s}-T_{0}\right) / \Delta l
$$

where $k$ is the bed conductivity coefficient, $L$ the length/height of the bed, $T_{0}$ the room temperature, and $\Delta l$ the wall thickness.

In these transport equations, $D_{s}$ represents the particle mixture coefficient due to random movements of the particles in the bed, $D_{a, e f f}$ the axial dispersion coefficient which is given by [16]:

$$
D_{a, e f f}=D_{O_{2, m}}+0.5 v_{g} d_{p}
$$

And $\lambda_{\text {eff }}$ the effective thermal conductivity coefficient given by [24]:

$$
\lambda_{\text {eff }}=\lambda_{\text {eff }, 0}+0.5 \lambda_{g} \operatorname{PrRe} / \varepsilon_{b}
$$

$D_{O_{2, m}}$ is the mass diffusion coefficient of oxygen in the air, $v_{g}$ the gas velocity, and $\lambda_{\text {eff }, 0}$ the conduction coefficient in the absence of gas flow.

The heat transfer coefficient by convection between the particles and the gas is:

$$
h=N u \lambda_{g} / d_{p}
$$

where $\lambda_{g}$ is the thermal conductivity of the gas and is [13]:

$$
\lambda_{g}=4.8 \times 10^{4} T_{g}^{0.717}
$$

And $N u$ is the Nusselt number defined by:

$$
N u=2 \varepsilon_{b}+0.295 R e^{0.625} \operatorname{Pr}^{0.33}
$$

where Pris the Prandtl number which is written:

$$
\operatorname{Pr}=\mu_{g} C_{p g} / \lambda_{g}
$$

where $c_{p g}$ is the specific heat of the gas.

The reaction heats are derived from the formula:

$$
Q_{\text {reaction }}=\Delta H_{\text {reaction }} \frac{\mathrm{d} M_{i g, s}}{\mathrm{~d} t}
$$

where $\Delta H_{r ? a c t i o n}$ and $\frac{\mathrm{d} M_{i g, s}}{\mathrm{~d} t}$ are respectively the enthalpy and the rate of the reaction. 


\subsection{Simplifying Assumptions}

To solve these equations, we propose a number of assumptions including:

- The diffusion coefficients of temperature and species are assumed to be constant;

- Particles of solid biomass used as fuel are supposed to be dry, which allows us to neglect the drying step during the combustion modeling;

- The particles are assumed to average size, which allows us to accept the hypothesis of the diffusion regime [25].

\subsection{System of Equations to Solve}

The new system obtained after taking into account the above assumptions is:

$\checkmark$ Transport equations of gas species:

$$
\varepsilon_{b} \rho_{g} \frac{\partial\left(Y_{i g}\right)}{\partial t}+\rho_{g} v_{g} \varepsilon_{b} \frac{\partial\left(Y_{i g}\right)}{\partial x}=\varepsilon_{b} D_{a, \text { eff }} \rho_{g} \frac{\partial}{\partial x}\left(\frac{\partial Y_{i g}}{\partial x}\right)+R_{Y_{i g}}
$$

where ig $=\left\{\mathrm{H}_{2} \mathrm{O}, \mathrm{O}_{2}, \mathrm{CH}_{4}, \mathrm{CO}_{2}, \mathrm{CO}, \mathrm{N}_{2}\right\}$.

$\checkmark$ Transport equations of temperatures (energy):

Gas Temperature:

$$
\varepsilon_{b} \rho_{g} c_{p g} \frac{\partial T_{g}}{\partial t}+\rho_{g} c_{p g} v_{g} \varepsilon_{b} \frac{\partial T_{g}}{\partial x}=\lambda_{g} \frac{\partial}{\partial x}\left(\frac{\partial T_{g}}{\partial x}\right)+W t_{g}
$$

Temperature of the solid bed:

$$
\left(1-\varepsilon_{b}\right) \rho_{s} c_{p s} \frac{\partial T_{s}}{\partial t}+\left(1-\varepsilon_{b}\right) \rho_{s} v_{s} c_{p s} \frac{\partial T_{s}}{\partial x}=\lambda_{e f f} \frac{\partial}{\partial x}\left(\frac{\partial T_{s}}{\partial x}\right)+W t_{s}
$$

Table 3 gives the expressions of the source terms of transport equations based

\begin{tabular}{|c|c|}
\hline Source terms & Expressions \\
\hline$R_{Y_{\text {full }}}$ & $-R_{d e v}-R_{c h a r}$ \\
\hline$R_{Y_{\text {datar }}}$ & $R_{\text {clar }}-R_{C_{(s)}}$ \\
\hline 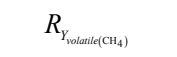 & $R_{d e v}-R_{g 1}$ \\
\hline$R_{Y_{\mathrm{O}_{2}}}$ & $-0.5 R_{C_{(s)}}-1.5 R_{g 1}-0.5 R_{g 2}$ \\
\hline$R_{Y_{\mathrm{CO}}}$ & $R_{C_{(2)}}+R_{g 1}-R_{g 2}$ \\
\hline$R_{\mathrm{rt}_{120}}$ & $2 R_{g 1}$ \\
\hline$R_{Y_{\mathrm{CO}_{2}}}$ & $R_{g 2}$ \\
\hline$W t_{g}$ & $h_{\mathrm{CH}_{4}} \frac{\partial\left(Y_{\mathrm{CH}_{4}}\right)}{\partial t}+h_{\mathrm{CO}} \frac{\partial\left(Y_{\mathrm{CO}}\right)}{\partial t}+h_{\mathrm{H}_{2} \mathrm{O}} \frac{\partial\left(Y_{\mathrm{H}_{2}}\right)}{\partial t}+h_{\mathrm{CO}_{2}} \frac{\partial\left(Y_{\mathrm{CO}_{2}}\right)}{\partial t}+h S\left(T_{S}-T_{g}\right)+Q_{l_{t}}$ \\
\hline$W t_{s}$ & 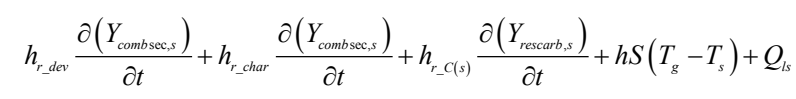 \\
\hline
\end{tabular}
on reaction rates.

Table 3. Summary of source terms of transport equations. 


\section{Summary of Reaction Equations}

Table 4 summarizes the main reaction models used in our model.

\section{Numerical Modeling}

\subsection{Numerical Methods}

As a reminder, we have seen in the theoretical tools that all the equations we are trying to solve are of the form:

$$
a_{0 i} \frac{\partial Y_{i}}{\partial t}=-a_{1 i} \frac{\partial Y_{i}}{\partial x}+b_{1 i} \frac{\partial}{\partial x}\left(\frac{\partial Y_{i}}{\partial x}\right)+W_{1 i}\left(Y_{i}, t\right)
$$

where $Y_{i}=$ species (solid $Y_{i s}$ or gaseous $Y_{i g}$ ), temperatures (of gaz $T_{g}$ or of solid bed $\left.\left.T_{s}\right)\right\}$.

As numerical methods we use:

An explicit method for space discretization and based on the explicit Euler:

The Euler method is based on an explicit finite difference method. It allows approximating the derived differential equations. This method is widely used in programming because it provides great writing simplicity.

$\checkmark$ An implicit method for the time resolution:

For solving the unstationnary term, we used an implicit method based on numerical differentiation formulas (NDFs) that solve stiff problems of differential equations to ordinary derivatives. For this, we put the equation in the form:

$$
\frac{\partial\left(Y_{i}\right)}{\partial t}=F\left(Y_{i}\right)
$$

With $F\left(Y_{i}\right)$ as: $F\left(Y_{i}\right)=A_{2 i} Y_{i}(j+1)+B_{2 i} Y_{i}(j)+C_{2 i} Y_{i}(j-1)+W_{2 i}\left(Y_{i}\right)$.

\subsection{Initial and Boundary Conditions}

The initial conditions are as follows: The combustion process is initiated above the fuel bed. For this, the upper surface of the bed is exposed to a temperature of about $850^{\circ} \mathrm{C}$. This temperature is that of the source of ignition. The exposure of

\begin{tabular}{|c|c|c|c|}
\hline Reaction (Reference) & Mechanism & Reaction rate & \\
\hline \multirow{2}{*}{$\begin{array}{l}\text { Wood pyrolysis } \\
\text { (Blasi [12]) }\end{array}$} & Wood $\longrightarrow$ Volatile & $\frac{\mathrm{d} M_{v o l}}{\mathrm{~d} t}=5.16 \times 10^{6} \exp \left(-10700 / T_{b}\right) M_{\text {wood }}$ & $(64)$ \\
\hline & Wood $\longrightarrow \operatorname{Char}(\mathrm{C})$ & & $(65)$ \\
\hline $\begin{array}{l}\text { Char combustion } \\
\text { (Smith [26]) }\end{array}$ & $\mathrm{Char}(\mathrm{C})+\frac{1}{2} \mathrm{O}_{2} \rightarrow \mathrm{CO}$ & $\begin{array}{l}\left.\frac{\mathrm{d} M_{\text {char }}}{\mathrm{d} t}\right)_{2}=-60 S C_{O_{2}} \frac{1}{1 / k_{r} \zeta+1 / k_{m}} \\
k_{r}=2.3 T_{p} \exp \left(-11100 / T_{b}\right)\end{array}$ & $(66)$ \\
\hline $\begin{array}{l}\text { Volatile combustion } \\
\text { (Siminski et al. [7]) }\end{array}$ & $\mathrm{C}_{x} \mathrm{H}_{y}+\left(\frac{1}{2} x+\frac{1}{4} y\right) \mathrm{O}_{2} \rightarrow x \mathrm{CO}+\frac{y}{2} \mathrm{H}_{2} \mathrm{O}$ & $\frac{\mathrm{d} C_{v o l}}{\mathrm{~d} t}=-59.8 T_{g} P^{0.3} C_{v o l}^{0.5} C_{\mathrm{O}_{2}} \exp \left(-12200 / T_{g}\right)$ & $(67)$ \\
\hline $\begin{array}{l}\text { Carbon monoxide combustion } \\
\text { (Bartok and Sarofim [18]) }\end{array}$ & $\mathrm{CO}+\frac{1}{2} \mathrm{O}_{2} \rightarrow \mathrm{CO}_{2}$ & $\frac{\mathrm{d} C_{\mathrm{CO}}}{\mathrm{d} t}=1.3 \times 10^{11} C_{\mathrm{CO}} C_{\mathrm{H}_{2} \mathrm{O}}^{1 / 2} C_{\mathrm{O}_{2}}^{1 / 2} \exp \left(-15105 / T_{\mathrm{g}}\right)$ & $(68)$ \\
\hline
\end{tabular}

Table 4. Summary of reaction models used in our model. 
the top of the bed at this temperature is done during a relatively short time necessary for the appearance of the flame front that gradually spread in the fuel bed.

For solid and gaseous species, we consider here the mass fractions and calculations are initialized at the onset of the flame front on the surface of the fuel bed.

Initial conditions $(t=0)$ :

$t=0$ and $x=0$ (at the bottom of the fuel bed): $Y_{\text {is }, 0}: Y_{\text {Fuel }, 0}=0.69 ; Y_{\text {char }, 0}=0.1$ and $Y_{\text {ig, } 0}: Y_{\text {volatile }, 0}=10^{-2} ; Y o_{2,0}=0.2 ; Y c o_{, 0}=10^{-2} ; Y h_{2} o_{, 0}=10^{-6} ; Y c o_{2.0}=10^{-6}$ et $Y n_{2.0}=0.747$.

$t=0$ and $x<H: T_{g, 0}=T_{S, 0}=T_{0}=300 \mathrm{~K}$, where $H$ represents the height of the fuel bed.

$t=0$ and $x=H$ (at the top of the fuel bed): $T_{g, 0}=T_{S, 0}=1123 \mathrm{~K}$.

Boundary conditions:

$t>0$ and $x=H$ (at the top of the fuel bed): $\frac{\mathrm{d} Y_{i s}}{\mathrm{~d} x}=\frac{\mathrm{d} T_{s}}{\mathrm{~d} x}=0 ;$ is $=\{$ dry fuel (Solid biomass), char, ash $\}$ and $\frac{\mathrm{d} Y_{i g}}{\mathrm{~d} x}=\frac{\mathrm{d} T_{g}}{\mathrm{~d} x}=0 ; i g=\left\{\mathrm{H}_{2} \mathrm{O}, \mathrm{O}_{2}, \mathrm{CH}_{4}, \mathrm{CO}_{2}, \mathrm{CO}\right.$, $\left.\mathrm{N}_{2}\right\}$.

\section{Results and Discussion}

The combustion process is initiated above the fuel bed. For this, the upper surface of the bed is exposed to a temperature of about $850^{\circ} \mathrm{C}$. This temperature is that of the source of ignition. The exposure of the top of the bed at this temperature is done during a relatively short time necessary for the appearance of the flame front that gradually spread in the fuel bed.

The combustion process is initiated above the fuel bed. For this, the upper surface of the bed is exposed to a temperature of about $850^{\circ} \mathrm{C}$. This temperature is that of the ignition source. The exposure of the surface of the bed at this temperature is for a fairly short time and necessary for the appearance of the flame front which will spread progressively in the fuel bed.

We have in Figure 4 the presentation of our burner. This burner is modeled on a model widely used in households. Figure 4 shows a modeling of said furnace, as well as the provision of thermocouples for measuring temperatures at different points. The thermocouple T9 (see Figure 4) is located $5 \mathrm{~cm}$ from the bottom of the oven, and the other thermocouples are spaced $5 \mathrm{~cm}$ each relative to the position of the other closest thermocouple.

The combustion process is performed in this burner, after introduction of the fuel. At the very beginning, the fuel (biomass) is introduced into the oven, up to a height of $45 \mathrm{~cm}$. The fuel introduced is supposed to be initially at room temperature.

When the upper surface of the fuel bed is exposed for a short time at a temperature of about $850^{\circ} \mathrm{C}$, this surface immediately undergoes a drying phenomenon with evaporation of moisture. After the drying phase, this high 
xposure temperature will cause pyrolysis of the fuel particles thus dried, allowing the release of volatiles and coal. These volatile gases will react in the gas phase. It follows a phenomenon of solid phase combustion of coal produced, and a gas phase combustion of volatiles (here mainly $\mathrm{CH}_{4}$ ) and $\mathrm{CO}$ produced during the combustion of coal and $\mathrm{CH}_{4}$.

Figure 5 shows the temperature curves of the fuel bed. Figure 5(a) shows the experimental results, Figure 5(b) is the one predicted by Shin \& Choi [1], and Figure 5 (c) curve is the one predicted by our model.

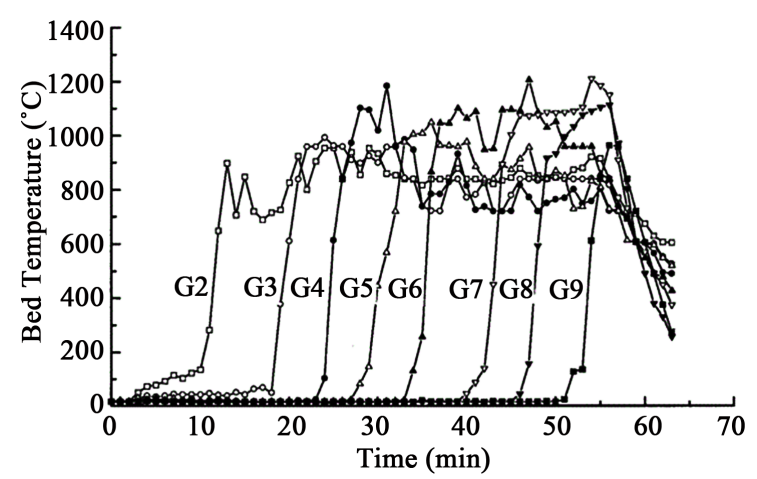

(a)

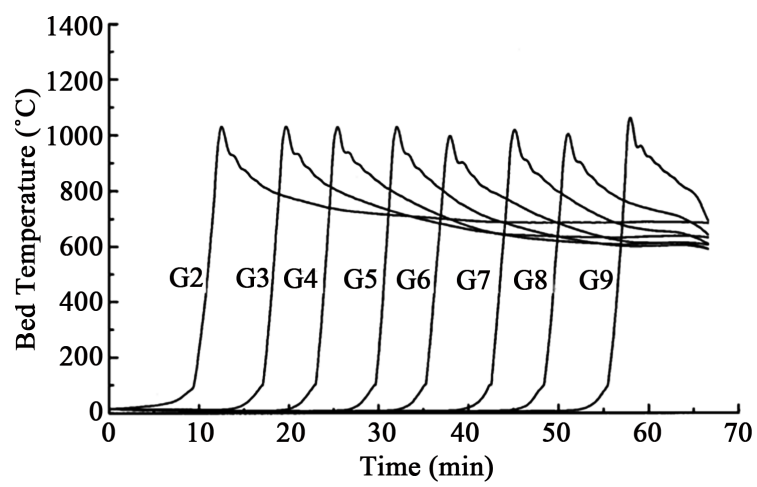

(b)

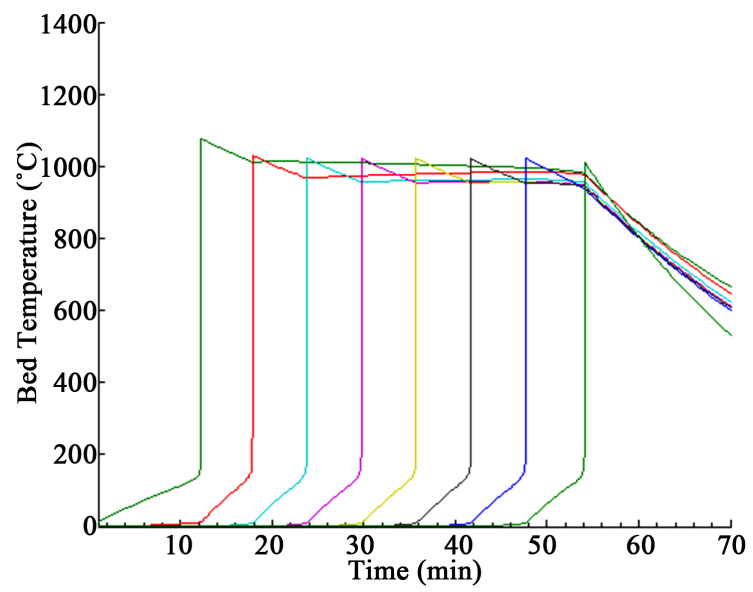

(c)

Figure 5. Evolution of temperature at each measurement point: (a) Experimental; (b) Numeric of Shin \& Choi [1]; (c) Prediction. 
Due to exposure to high temperatures of the upper surface of the fuel bed, the temperature in the bed increases rapidly, and the progression of the flame in the bed is gradually felt at the thermocouple T2 (see Figure 4 for its layout) which begins to heat up. At this time, the thermocouple T3 (respectively G3) located at $5 \mathrm{~cm}$ from T2 (respectively G3) remains almost always at room temperature, proof that the flame front has not yet arrived at this level. This weak progression of the flame front can be explained not only by the low conductivity of the fuel bed, but also by the supply air that always arrives at room temperature, thereby cooling the bed continuously. After a while, the temperature of thermocouple T3 (see Figure 5) explodes in its turn, and this same phenomenon is observed successively for thermocouples T4 to T9 (respectively G4 to G9). The first peak of temperature is observed around 10 minutes, and the second peak of temperature, measured by the thermocouple T3, it meanwhile obtained around 18 minutes. The flame front progressively progresses to the bottom of the bed, leaving ash on its way. And when this flame front reaches the bed, then the fuel is completely transformed into ash and the combustion ends. The hot ash produced is cooled by the supply air, which explains the rapid temperature drop of thermocouple T9 (respectively G9) as shown in Figure 5(c) (respectively 5-a).

The numerical temperature curves of thermocouples T2 to T9 have substantially the same ignition delays as the respective experimental curves G2 to G9 (see Figure 5). Referring to ignition delays, temperature peaks and also the shape of the temperature curves at the post-combustion phase, we can say that our numerical curves of temperature (see Figure 5(c)) seem to stick better with the experimental measurements (see Figure 5(a)).

Figure 6 shows the prediction curve by our model of the variation of the dry fuel mass fraction (obtained after the drying phase). These curves are obtained for each observation point, and these points correspond here to the positions of the different thermocouples T2 to T9 as indicated in Figure 4.

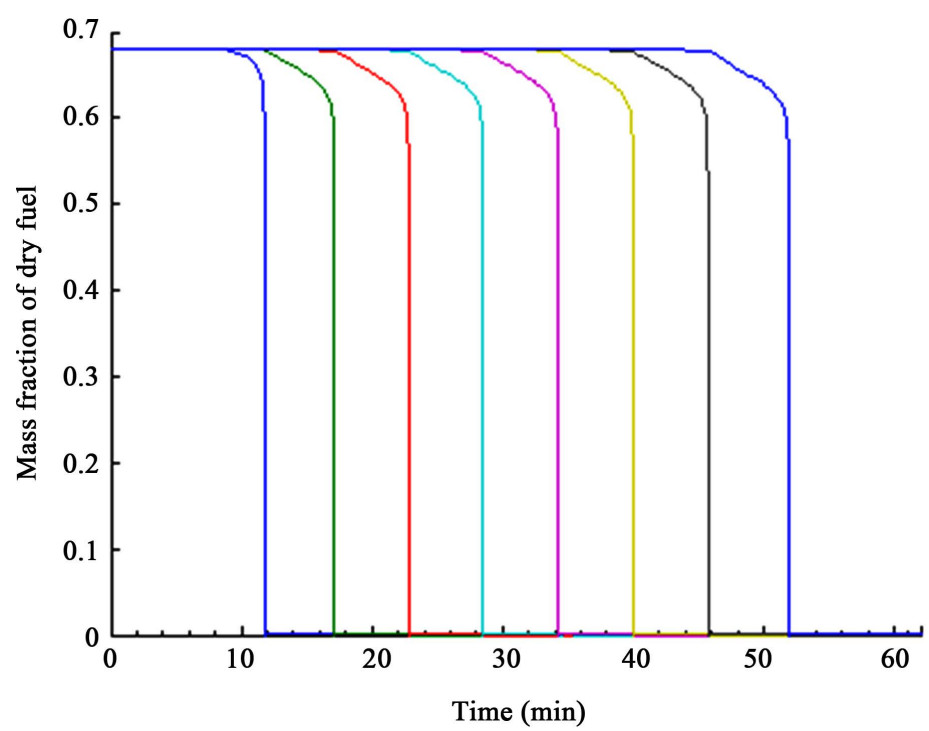

Figure 6. Change in mass fraction of dry fuel at each observation point. 
For the position of thermocouple T2, we observe a first plateau up to about 10 minutes, at which time the mass fraction of dry fuel decreases sharply until it vanishes, proof that the pyrolysis process is complete. After this time, the mass fraction of dry fuel is kept at 0 , thus forming a plateau again at this value. For the position of the thermocouple T3, the same phenomenon is observed with the only difference that the pyrolysis is carried out a little later, or about 18 minutes.This proves that the heat has progressed in the furnace, and that the rise in temperature due to this heat supply is already sufficient to cause the pyrolysis of our fuel.

This proves that the heat has progressed in the furnace, and that the rise in temperature due to this heat supply is already sufficient to cause the pyrolysis of our fuel. We then observe and successively the same phenomena for the points of observation of T4 to T9, and this at different times. These curves therefore have the same profile and differ only in the ignition delay. The lags between the ignition delays of these different profiles are due to the convection and diffusion phenomena that create a transport in the bed.

During the propagation of the flame front along the bed, there is degradation of the fuel with production of ash and energy, which causes a loss of mass. This loss of mass is characterized by a gradual decline in the volume or height of the bed during combustion. This decrease in bed height modeled in Figure 1 is shown in Figure 7. Figure 7(a) from Shin and Choi [1] presents the experimental results obtained by measuring the decrease in the height of the fuel bed, and Figure 7(b) shows the numerical results obtained at fixed observation points. These numerical and experimental results are similar.

The significant decrease in bed mass observed at each stage correspond to the temperature peaks observed previously, and these levels are due to the limited number of measuring or observation points. The loss of mass in the fuel bed is normal and can be explained by the transformation of the starting fuel into energy, ashes and burnt gases.

Figure 8 shows the speed of propagation of the flame front along the fuel bed, a speed predicted by our model. We find that the flame front progresses steadily along the fuel bed. However, it should be noted that when the flame front arrives at the end of the bed (located $45 \mathrm{~cm}$ from the initial bed height), then the combustion stops, and the flame front is stopped at this position because not only the starting fuel is totally degraded and turned into ashes, but also the hot ashes produced are cooled by the air supply that always arrives at room temperature. As a result, the speed of propagation of the flame at the bed is therefore zero.

Figure 9 shows the influence of the size of the fuel particles on the propagation speed of the flame front.

This figure presents the experimental results [1] and those predicted by our model. We observe a difference of about $17 \%$ between these two results, the measured values being smaller than the values predicted by the numerical model, but the slopes presented by these two results are similar. We find that as 


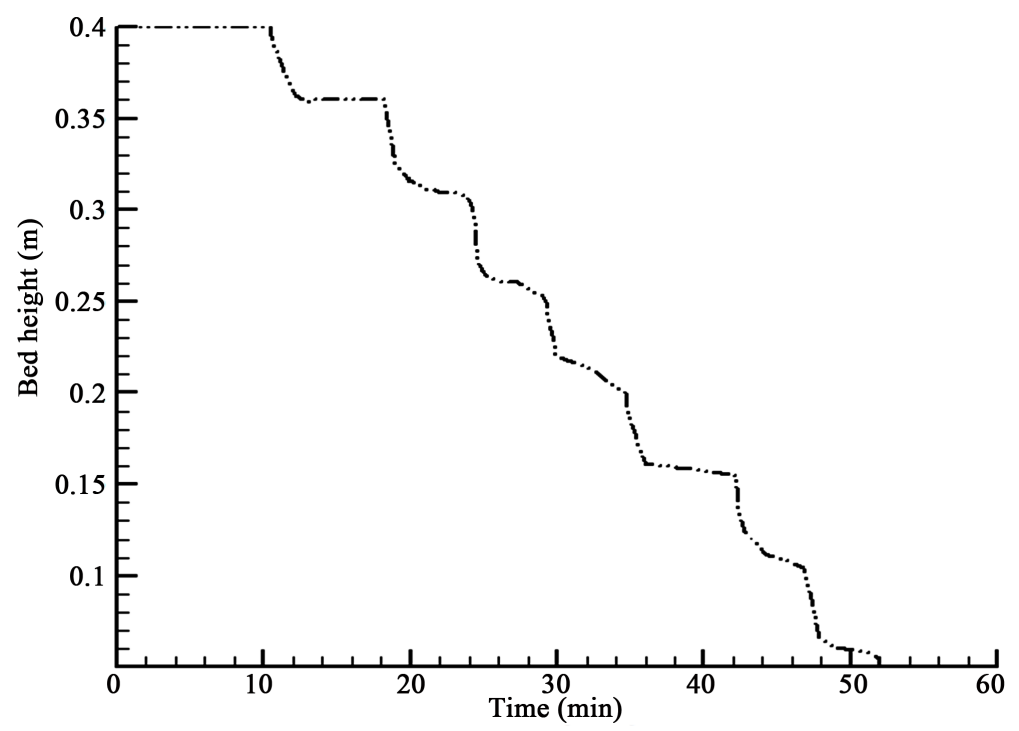

(a)

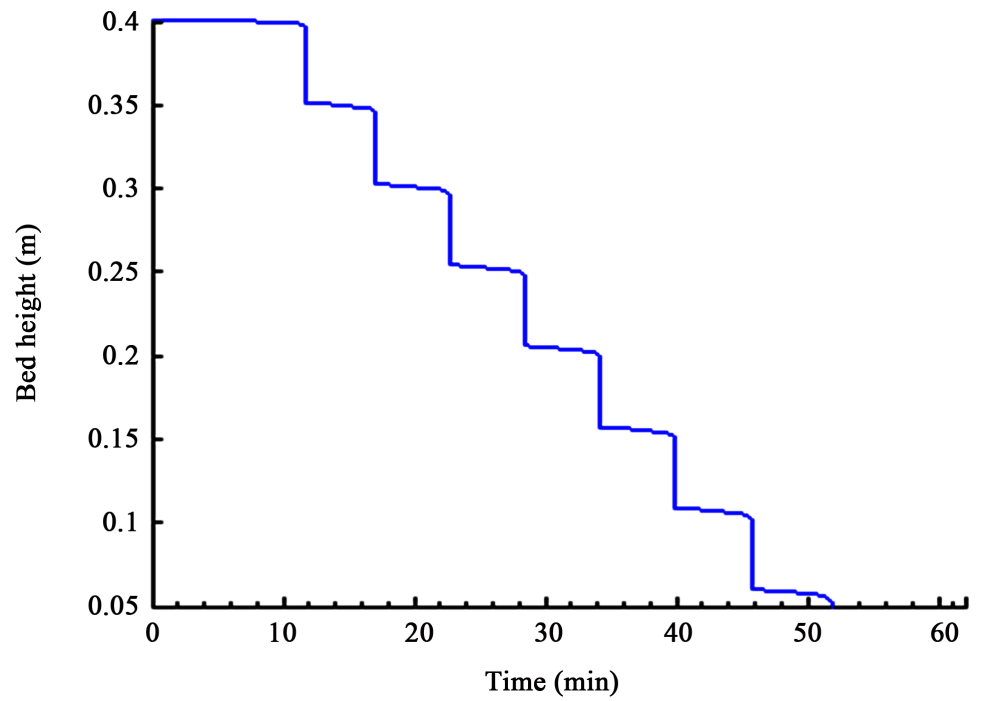

(b)

Figure 7. Loss of mass of the fuel bed: (a) measurement; (b) prediction.

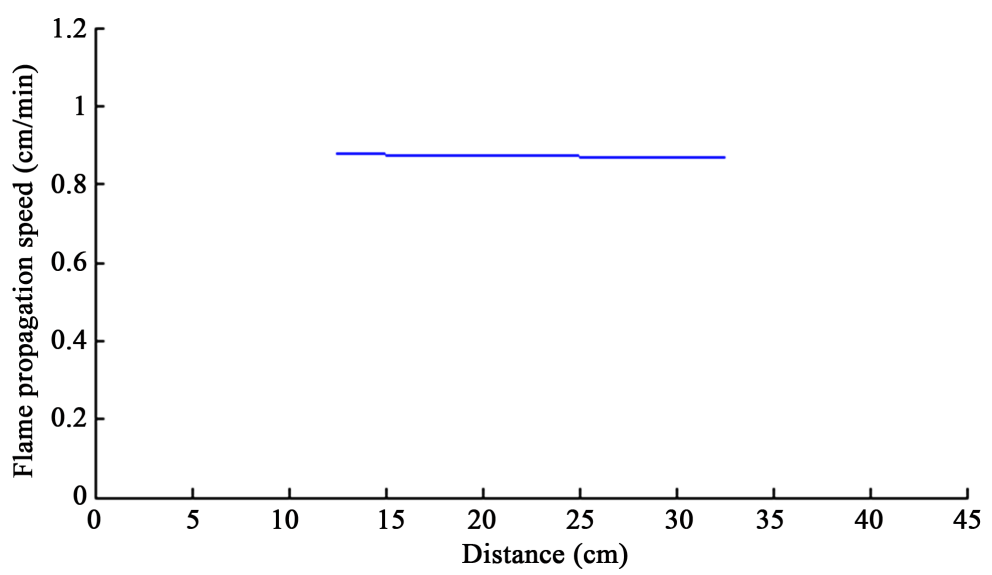

Figure 8. Speed of propagation of the flame front along the bed. 


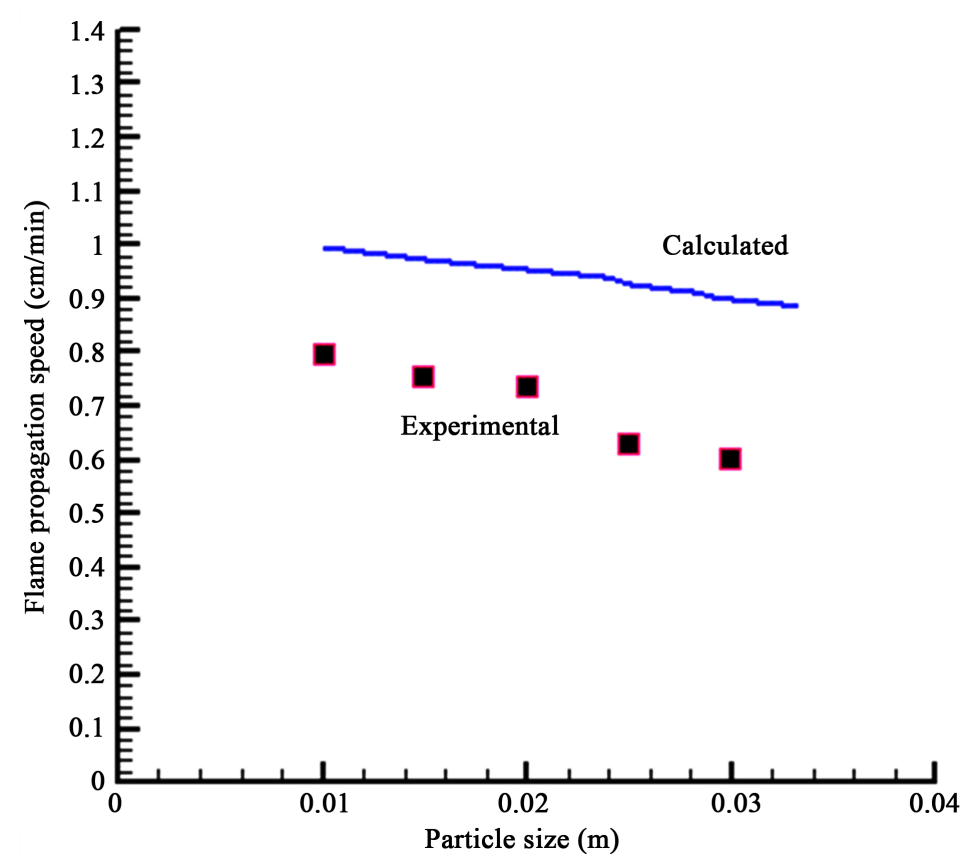

Figure 9. Effect of particle size on the propagation velocity of the flame front.

the particle size increases, the speed of propagation of the flame decreases. To explain this decrease in the propagation velocity of the flame front, we can say that when the particle size increases, the surface per unit mass decreases, and consequently the cooling effect of the air also decreases.In order to make the combustion stable, therefore, a higher maximum air ratio is required than in the case of smaller particles. Increasing the particle size therefore increases the drying time, and therefore the burning time of the fuel particles, and so the flame front evolves more slowly, which explains the decrease in flame front velocity when particle size increases, as shown in Figure 9.

\section{Conclusions}

The study of biomass combustion was carried out here on a fixed bed grid. For this study, we have modeled the different stages of solid combustion in terms of mathematical equations of evolution of species and energy. Multiphasic combustion is a physicochemical complexity. We used a 1-D model here. This $1-\mathrm{D}$ modeling of the transport equations allowed us to propose a numerical model of multiphase combustion of biomass.

This multiphasic combustion is initiated by exposing the upper surface of the fuel bed to a temperature of about $850^{\circ} \mathrm{C}$. The flame front that emerges from this exposure to high temperatures will progress and spread gradually throughout the bed. The ignition of the combustion at the measuring points is justified by the exponential increase of the temperatures of the different thermocouples, the temperature peaks exceeding the $1000^{\circ} \mathrm{C}$. The degradation of the solid fuel during combustion is justified by the decrease of the volume or the loss of mass, which is observed by the decrease of the height of the combustible bed. 
The distribution of the fuel on the grid, the size of the particle, the ignition temperature and also the supply air flow are important parameters for obtaining good combustion.

Here, the energy produced during combustion in the form of heat can be used for example in households for cooking meals, drying fruit, etc.

In view of the results obtained, and with some differences, we can say that our model reproduces the physico-chemical and heat transfer phenomena that occur during combustion in this fixed bed.

\section{Conflicts of Interest}

The authors declare no conflicts of interest regarding the publication of this paper.

\section{References}

[1] Shin, D. and Choi, S. (2000) The Combustion Of Simulated Waste Particules in a Fixed Bed. Combustion and Flame, 121, 167-180. https://doi.org/10.1016/S0010-2180(99)00124-8

[2] Badzioch, S. and Hawksley, P.G.W. (1970) Kinetics of Thermal Decomposition of Pulverized Coal Particles. Industrial \& Engineering Chemistry Process Design and Development, 9, 521-530. https://doi.org/10.1021/i260036a005

[3] Kobayashi, H., Howard, J.B. and Sarofim, A.F. (1977) Coal Devolatilization at High Temperatures. The Sixteenth Symposium (International) on Combustion, Massachusetts Institute of Technology, Cambridge, Massachusetts, 15-20 August 1976, Vol. 16, 411-425.

[4] Baum, M.M. and Street, P.J. (1971) Predicting the Combustion Behavior of Coal Particle. Combustion Science and Technology, 3, 231-243. https://doi.org/10.1080/00102207108952290

[5] Fletcher, T.H., Kerstein, A.R., Pugmire, R.J. and Grant, D.M. (1990) Chemical Percolation Model for Devolatilization: 2. Temperature and Heating Rate Effects on Product Yields. Energy and Fuels, 4, 54. https://doi.org/10.1021/ef00019a010

[6] Field, M.A. (1969) Rate of Combustion of Size-Graaded Fractions of Char from a Low Rank Coal between 1200 K - 2000 K. Combustion and Flame, 13, 237-252. https://doi.org/10.1016/0010-2180(69)90002-9

[7] Siminski, V.J., Wright, F.J., Edelman, R.B., Economos, C. and Fortune, O.F. (1972) Research on Methods of Improving the Combustion Characteristics of Liquid Hydrocarbon Fuels'. Rept. AFAPL TR 72-74, Vols. I and II, Air Force Aeropropulsion Laboratory, Wright Patterson Air Force Base, Dayton, Ohio.

[8] Rogaune, Y. (2005) Production de chaleur à partir du bois-Combustible et appareillage. Technique de l'ingénieur, BE 8 747, Vol. 1.

[9] Benkoussas, B., Consalvi, J.L., Porterie, B., Sardoy, N. and Loraud, J.C. (2007) Modelling Thermal Degradation of Woody Fuel Particles. International Journal of Thermal Sciences, 46, 319-327. https://doi.org/10.1016/j.ijthermalsci.2006.06.016

[10] Johansson, R., Thunman, H. and Leckner, B. (2007) Influence of Intraparticle Gradients in Modeling of Fixed Bed Combustion. Combustion and Flame, 149, 49-62. https://doi.org/10.1016/j.combustflame.2006.12.009

[11] Elfasakhany, A. and Bai, X.S. (2006) Modelling of Pulverised Wood Combustion: A 
Comparison of Different Models. Progress in Computational Fluid Dynamics, 6, 188-199. https://doi.org/10.1504/PCFD.2006.010027

[12] Blasi, C.D. (1993) Modeling and Simulation of Combustion Processes of Charring and Non-Charring Solid Fuels. Progress in Energy and Combustion Science, 19, 71-104. https://doi.org/10.1016/0360-1285(93)90022-7

[13] Zhou, H., Jensen, A.D., Glarborg, P., Jensen, P.A. and Kavaliauskas, A. (2005) Numerical Modeling of Straw Combustion in a Fixed Bed. Fuel, 84, 389-403. https://doi.org/10.1016/j.fuel.2004.09.020

[14] Desroches-Ducarne, E.J., Dolignier, C., Marty, E., Martin, G. and Delfosse, L. (1998) Modelling of Gaseous Pollutants Emissions in Circulating Fluidized Bed Combustion of Municipal Refuse. Fuel, 77, 1399-1410. https://doi.org/10.1016/S0016-2361(98)00060-X

[15] Kausley, S.B. and Pandit, A.B. (2010) Modelling for Solid Fuel Stoves. Fuel, 89, 782-791. https://doi.org/10.1016/j.fuel.2009.09.019

[16] Yang, Y.B., Goh, Y.R., Zakaria, R., Nasserzadeh, V. and Swithenbank, J. (2002) Mathematical Modeling of MSW Incineration on a Travelling Bed. Waste Management, 22, 369-380. https://doi.org/10.1016/S0956-053X(02)00019-3

[17] Howard, J.B., William, G.C. and Fine, D.H. (1973) Kinetics of Carbon Monoxide Oxidation in Postflame Gases. Symposium (International) on Combustion, 14, 975-986. https://doi.org/10.1016/S0082-0784(73)80089-X

[18] Bartok, W. and Sarofim, A. (1991) Fossil Fuel Combustion. John Wiley, New York.

[19] Bryden, K.M. and Ragland, K. (1973) Numerical Modeling of a Deep, Fixed Bed Combustor. Energy \& Fuels, 10, 269-275. https://doi.org/10.1021/ef950193p

[20] Thunman, H. and Leckner, B. (2007) Thermo Chemical Conversion of Biomass and Wastes. Nordic Graduate School Biofuel GS-2, Chalmers, Goteborg, Sweden, 19-23 November 2007.

[21] Thunman, H. and Leckner, B. (2002) Thermal Conductivity of Wood-Models for Different Stages of Combustion. Biomass and Energy, 23, 47-54. https://doi.org/10.1016/S0961-9534(02)00031-4

[22] Dwivedi, P.N. and Upadhyay, S.N. (1977) Particle-Fluid Mass Transfer in Fixed and Fluidized Beds. Industrial \& Engineering Chemistry Process Design and Development, 16, 157-165. https://doi.org/10.1021/i260062a001

[23] Bruch, C. and Peter, B. and Nussbaumer, T. (2003) Modelling Wood Combustion under Fixed Bed Conditions. Fuel, 82, 729-738.

https://doi.org/10.1016/S0016-2361(02)00296-X

[24] Fjellerup, J., Henriksen, U., Jensen, A.D., Jensen, P. and Glarborg, P. (2003) Heat Transfer in a Fixed Bed of Straw Char. Energy \& Fuels, 17, 1251-1258. https://doi.org/10.1021/ef030036n

[25] Huttunen, M., KJäldman, L. and Saastamoinen, J. (2004) Analysis of Grate Firing of Wood with Numerical Flow Simulation. IFRF Combustion Journal, Article No. 200401.

[26] Smoot, L.D. and Smith, P.J. (1985) Coal Combustion and Gasification. Plenum Press, New York. https://doi.org/10.1007/978-1-4757-9721-3 


\section{Nomenclature}

$Y_{i g}:$ Mass fraction of the gas species $i$

$Y_{i s}$ : Mass fraction of solid species $i$

$u_{s}:$ Lowering speed of the solid fuel $[\mathrm{m} / \mathrm{s}]$

$\lambda_{s}$ : Thermal conductivity of solid

$\lambda_{g}$ : Thermal conductivity of gas

$\mu_{g}$ : Dynamic viscosity of gas

$k$. Bed conductivity coefficient

$M_{i}:$ Molar mass of species $i[\mathrm{~g} / \mathrm{mol}]$

$u_{g}:$ Superficial gas velocity $[\mathrm{m} / \mathrm{s}]$

$P_{\mathrm{O}_{2}}$ : Partial pressure of oxygen $[\mathrm{Pa}]$

$h_{f_{i}}^{\circ}$ : Enthalpy of formation of species $i[\mathrm{~J} / \mathrm{mol}]$

Lvap: Latent heat of vaporization of water $[\mathrm{J} / \mathrm{kg}]$

$S$ : Exchange surface of the particles of the bed $\left[\mathrm{m}^{2} / \mathrm{m}^{3}\right]$

$D_{i}$ : Mass diffusion coefficient of species $i$

$R_{Y_{i}}$ : Source term of the transport equation of species $i$

$W t_{g}$ : Term source of the transport equation of $T_{g}$

$W t_{s}$ :Term source of the transport equation of $T_{S}$

$t:$ Time $[\mathrm{s}]$

$Y_{i g, 0}:$ Initial value of $Y_{i g}$

$Y_{i s, 0}$ : Initial value of $Y_{i s}$

$T_{S}$ : Temperature of solid [K]

$T_{g}$ : Gas Temperature $[\mathrm{K}]$

$T_{S, 0}:$ Initial value of $T_{S}[\mathrm{~K}]$

$T_{g, 0}$ : Initial value of $T_{g}[\mathrm{~K}]$

$T_{a}$ : Ambient temperature $[\mathrm{K}]$

$Q_{r i}:$ Heat of the reaction ri [W]

$\varepsilon_{b}$ : Porosity of fuel bed

$d_{p}$ : Particle diameter [m]

$d x$. Space step $[\mathrm{m}]$

$\rho_{i}$ : Density of body $i\left[\mathrm{~kg} / \mathrm{m}^{3}\right]$

$h$ : Convective heat transfer coefficient $\left[\mathrm{W} / \mathrm{m}^{2} \mathrm{~K}\right]$

$H_{s}$ : Humidity on dry

$H_{b}$ : Humidity on crude

$E_{a}$ : Activation energy [J]

$h_{r_{-} r i}:$ Heat of the reaction ri $[\mathrm{J} / \mathrm{kg}]$

$\Omega_{\text {act }}$ : Ash Factor

Greek letters

$\lambda_{s}$ : Thermal conductivity of solid

$\lambda_{g}$ : Thermal conductivity of gas

$\mu_{g}$ : Dynamic viscosity of gas

$\xi$ : Thermal conductivity of solid

$\varepsilon_{b}$ : Porosity of fuel bed 
$\rho_{i}$ : Density of body $i$

$\Omega_{a c t}$ : Ash Factor

Abbreviations

GHGs: Greenhouse gases

HW: Household waste 